the marrow specimens were suspended in reconstituted dried plasma or in serum which had been heated to $56^{\circ} \mathrm{C}$. for one hour, instead of in unheated serum. As it is known that adhesion of leucocytes requires the presence of some thermolabile factor in serum $^{4}$, this effect was thought to be due to adhesion of the cells in unheated serum. To check this point, a grease-free coverslip was laid on the floor of each culture bottle, and was removed, washed in running tap water, and stained at the same time as the smears and total counts were made (that is, after 1-4 days). The photograph (Fig. 2) shows two such coverslips, the left from a 48-hour culture in heated serum, the right from a similar culture in unheated serum. The cells involved were always predominantly myeloid and monocytoid. No adhesion of nucleated red cells was ever seen. The density of the deposit was about 300,000 per square centimetre, this figure being of the same order of magnitude as that obtained from the silicone experiments.

Department of Clinical Pathology,

H. J. F. CAIRNS

L. G. LaJTha

Radeliffe Infirmary, Oxford.

${ }^{1}$ Sherrington, C., Proe. Roy. Soc., 55, 161 (1894).

'Rusznyak, St., Löwinger, S., and Lajtha, L., Nature, 160, 757 (1947).

'Jaques, L. B., Fidlar, E., Feldsted, E. T., and Macdonald, A. G., Canad. Med. A880c. J., 55, 26 (1946).

'Barikine, W., Z. Immunitätsforsch., 8, 72 (1910).

\section{Effect of Adenosine Triphosphate on Monolayers of Myosin}

LITTLE is known about the behaviour of myosin in monomolecular layers. Communications previously published on this subject ${ }^{1,2}$ appeared at an early stage of the study of myosin, that is, before SzentGyörgyi and his school ${ }^{3}$ had shown that myosin consists of at least two different proteins, actin and myosin proper. In connexion with work in this laboratory ${ }^{4}$ on the interaction between high-energy phosphate compounds and the different components of myosin, the investigations have been extended to monolayers of these proteins.

The influence of adenosine triphosphate and re. lated substances on the force-area relationships of monolayers of actin-free myosin and the complex actomyosin has been studied. The proteins in question were isolated by Szent-Györgyi's method ${ }^{5}$. Actin was obtained in aqueous solution, actomyosin and myosin proper in salt solutions $(0.6 M$ potassium chloride). The solutions were diluted to approximately $0 \cdot 2$ per cent (referred to dry-weight determinations) and roughly filtered before spreading.

Actin spreads on water or salt solutions, whereas actomyosin and actin-free myosin spread effectively only on solutions of considerable ionic strength. The most favourable conditions were provided by using a veronal buffer of $p H 5 \cdot 3$, made $0 \cdot 6 M$ with respect to potassium chloride, in all experiments.

Each film was allowed to spread for four minutes at zero pressure before readings were taken. Experimental data for a sample of actomyosin are recorded in the accompanying graph. When adenosine triphosphate is added to the substrate to a final concentration of $0.05 \mathrm{mgm} . / \mathrm{ml}$. $(0.00005 \mathrm{M})$, the force-area curve for the monolayer is changed. The sudden increase in slope of the curve now occurs at a larger area than before. The effect of adenosine triphosphate is highly specific, as adenosine diphosphate, and inorganic tripolyphosphate, pyro-

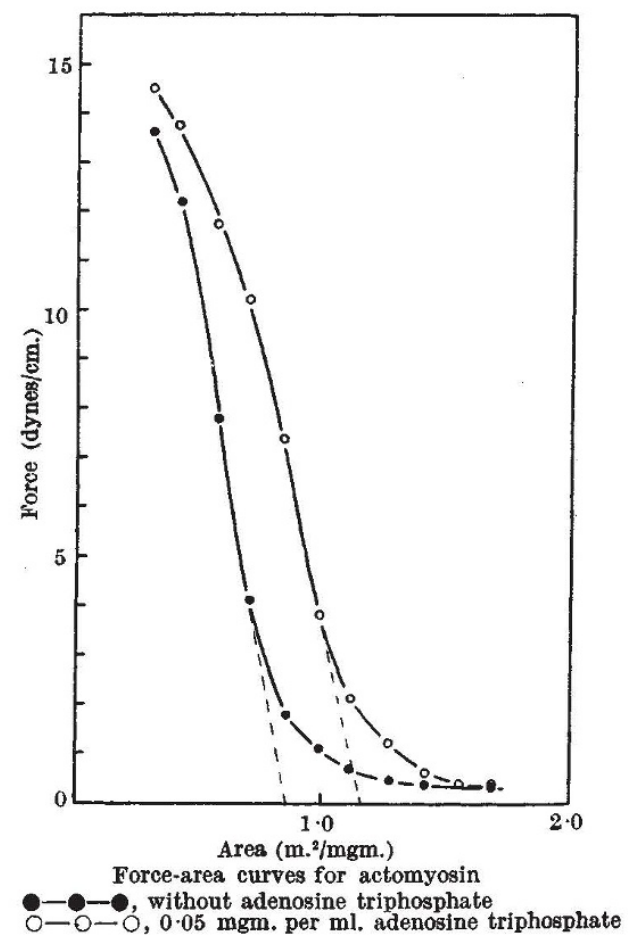

phosphate and orthophosphate employed in the same molar concentrations have no visible effect. Only on addition of these substances in concentrations approximately ten times higher are similar effects obtained. Owing to the uncertainty in the dry-weight determinations, too much emphasis should not be laid on the absolute values of the area in the diagram.

The data obtained in several experiments indicate that the expanding effect is more pronounced with monolayers of myosin proper than with those of actomyosin. In the latter the area at zero compression increases after addition of adenosine triphosphate by about 30 per cent, whereas in the case of myosin proper the average increase amounts to 100 per cent. In both cases the gradient of the approximately rectilinear part of the curve decreases when adenosine triphosphate is added. Actin shows no reaction with adenosine triphosphate or the other phosphate compounds investigated.

The result indicates that adenosine triphosphate in some way combines with myosin and causes it to expand, thereby increasing the surface pressure of the monolayers in the condensed state. According to a verbal communication from Dr. D. F. Cheesman, it is probable that the effects described above may be due rather to the spreading kinetics of myosin than to the properties of the fully spread films.

My thanks are due to Prof. E. K. Rideal and Dr. D. F. Cheesman, of the Davy Faraday Laboratory at. the Royal Institution, London, for hospitality and valuable advice. The preliminary experiments of the investigation were made in that Laboratory. Agnete Munch-Petersen

Institute of Neurophysiology,

University of Copenhagen. May 12.

Moss and Rideal, Nature, 186, 260 (1935).

2 Dervichian, Nature, 44, 629 (1939).

Stud. Inst. Med. Chem., Univ. Szeged, 2 (1942).

Buchthal, Deutsch, Knappeis and Munch-Petersen, Acta Physiol. Scand, 18, 167 (1947).

"Szent-Györgyi, "Chemistry of Muscular Contraction" (1947). 